\title{
Research on the Utilization Efficiency of Nitrogen by Winter Wheat under Different Water and Fertilizer Regulation and Cultivation Modes
}

\author{
Jinbo Zhao1, Ming Chen', Jinghua Zhou ${ }^{2 *}$ \\ ${ }^{1}$ State Key Laboratory of Environment Simulation and Pollution Control, School of Environment, Beijing Normal University, \\ Beijing, China \\ ${ }^{2}$ State Key Laboratory of Environment Simulation and Pollution Control, School of Environment, Tsinghua University, \\ Beijing, China \\ Email: *shc-den@tsinghua.edu.cn
}

How to cite this paper: Zhao, J.B., Chen, M. and Zhou, J.H. (2021) Research on the Utilization Efficiency of Nitrogen by Winter Wheat under Different Water and Fertilizer Regulation and Cultivation Modes. Open Access Library Journal, 8: e7057. https://doi.org/10.4236/oalib.1107057

Received: June 9, 2021

Accepted: July 9, 2021

Published: July 12, 2021

Copyright $\odot 2021$ by author(s) and Open Access Library Inc.

This work is licensed under the Creative Commons Attribution International License (CC BY 4.0).

http://creativecommons.org/licenses/by/4.0/

\section{(c) (i) Open Access}

\begin{abstract}
Since 2016 China liberalized its third-child policy, which resulted in an increase of millions of people every year and therefore China must ensure annual output increases. The utilization efficiency of water and fertilizer is one of the most important keys to mitigating the food crisis. Artificial intelligence technology will be the development of Chinese agriculture. However, the physical and chemical properties of soil, the selection of seeds, the characteristics of different crops, the proportion of water and fertilizer regulation, and the different tillage methods all affect the grain output and the sustainable development of tillage mode. The purpose of this paper is to find the direct relationship between tillage mode and water and fertilizer regulation, and summarize some rules. To provide data and theoretical support for the implementation of China's modern agriculture. Therefore, winter wheat (wheat breed: Ji wheat 22) as the study crop was targeted, two irrigation methods: traditional irrigation (A) and water-saving irrigation (B) were selected, three fertilization factors: no fertilization (CK), traditional fertilization (FC) and optimized fertilization (FO) were chosen. Water and nitrogen fertilizer were used as control variables. This paper analyzes the environmental benefits of winter wheat irrigation and fertilization and provides a theoretical basis for rotation system efficiency and the sustainable production of winter wheat in a plain area. The results suggested that the water-saving irrigation mode had significantly better nitrate absorption efficiency of soil. The water-saving model is more conducive to improving the nitrogen absorption efficiency by the soil.
\end{abstract}




\section{Subject Areas}

Agricultural Engineering

\section{Keywords}

Nitrogen, Fertilizer, Soil, Cultivation Mode, Winter Wheat

\section{Introduction}

Hebei province is a big province with resource-based water shortage, and the shortage of water resources has become the main limiting factor to the sustainable development of agriculture in Hebei province [1] [2]. The rapid growth of population makes the total amount of fertilizer used in agriculture increase year by year, but the efficiency of fertilizer use decreases year by year, which also indirectly increases the farming cost. The excessive application of nitrogen fertilizers is also the main cause of agricultural nonpoint source pollution. Winter wheat is one of the main crops in Hebei province. Generally in late September to early October sowing, the next year from the end of May to mid-late June mature [3]-[9].

\section{Research Methods}

This paper studied winter wheat (wheat breed: Ji wheat 22) on changes in soil nitrogen leaching in the regulation measures of water and fertilizer. A field experiment was carried out in the west plain of Baiyangdian Lake. The experiment was divided into two regions: traditional irrigation (A) and water-saving irrigation (B), and each region was divided into five regulatory factor zones: no fertilization (CK), traditional fertilization (FC), optimal fertilization (FO), optimal fertilization + soil conditioner (FO + PAM), optimal fertilization + liquid plastic film $(F O+L F)$. There were 10 treatments (see Table 1), and each treatment was repeated for 3 times. The area of each treated cell is $9.5 \times 4.5=42.75 \mathrm{~m}^{2}$, and there are 30 cells in total, which are arranged randomly in groups. The interval of each cell is $1 \mathrm{~m}$, and a $2 \mathrm{~m}$ protection line is set outside the large area. Traditional irrigation uses ridges and furrows to carry water and flood irrigation with water meters. Sprinkler irrigation was adopted for water-saving irrigation, which reduced the amount of water by $30 \%$ compared with traditional irrigation. The irrigation times of the two irrigation methods were the same. The dosage of conventional fertilization and optimal fertilization is shown in Table 1. Phosphate and potassium fertilizer were all applied in the form of base fertilizer and shallow toppling before wheat sowing. 70\% basal application and 30\% topdressing combined with irrigation at wheat jointing stage. The liquid plastic film covering amount was $30 \mathrm{~kg} / \mathrm{hm}^{2}$, and it was sprayed in wheat and maize seedling stage respectively. Before spraying, dilute the liquid film with water 30 times, and spray evenly on the whole community with agricultural sprayer. The dosage 
Table 1. The experiment design of winter wheat-summer maize field.

\begin{tabular}{cccccc}
\hline $\begin{array}{c}\text { Serial } \\
\text { number }\end{array}$ & $\begin{array}{c}\text { Treatment } \\
\text { method }\end{array}$ & $\begin{array}{c}\text { Fertilizer } \\
(\mathrm{N}-\mathrm{P}-\mathrm{K}) \\
\left(\mathrm{kg} / \mathrm{hm}^{2}\right)\end{array}$ & $\begin{array}{c}\text { Soil conditioner } \\
\left(\mathrm{kg} / \mathrm{hm}^{2}\right)\end{array}$ & $\begin{array}{c}\text { Liquid film } \\
\left(\mathrm{kg} / \mathrm{hm}^{2}\right)\end{array}$ & $\begin{array}{c}\text { Irrigation } \\
\text { amount } \\
\left(\mathrm{m}^{3} / \mathrm{hm}^{2}\right)\end{array}$ \\
\hline 1 & A-CK & 0 & 0 & 0 & 2250 \\
2 & A-FC & $275-150-60$ & 0 & 0 & 2250 \\
3 & A-FO & $225-150-90$ & 0 & 0 & 2250 \\
4 & A-FO + PAM & $225-150-90$ & 45 & 0 & 2250 \\
5 & A-FO + LF & $225-150-90$ & 0 & 30 & 2250 \\
6 & B-CK & 0 & 0 & 0 & 1500 \\
7 & B-FC & $275-150-60$ & 0 & 0 & 1500 \\
8 & B-FO & $225-150-90$ & 0 & 0 & 1500 \\
9 & B-FO + PAM & $225-150-90$ & 45 & 0 & 1500 \\
10 & B-FO + LF & $225-150-90$ & 0 & 30 & 1500 \\
\hline
\end{tabular}

of soil conditioner was $30 \mathrm{~kg} / \mathrm{hm}^{2}$, applied before sowing, and the soil was lightly turned over. Other field management measures were carried out in accordance with farmers' traditions. The experiment was carried out from October 2015 to June 2016 at Baizhuang Village and the detailed instruction about experiment methods has been published on the previous work [10].

\section{Result and Analysis}

\subsection{Effect of Water and Fertilizer Regulation on Soil Nitrate Content}

Nitrate is the main nitrogen form of soil mineral nitrogen and crop absorption in dry land, and it plays a major role in crop growth and development. With an increase in the nitrogen application rate in soil, the residual amount also increases. As the residual nitrate in soil is affected by air temperature and precipitation, large amounts of nitrogen fertilizers will increase the deeper soil nitrate in rain-fed areas. The reason may be related to the migration of nitrate to the deeper soil layers under concentrated precipitation or irrigation conditions. The vertical distribution of nitrate by different nitrogen fertilizer treatments was basically consistent in all the growth stages of winter wheat under the different irrigation methods, which shows that the soil nitrate content decreases gradually with the increase in soil depth with different reduction ranges.

As shown in Figure 1, in the regreening stage of winter wheat, the more nitrogen fertilizer applied, the higher the soil nitrate content will be. The soil nitrate content under the $\mathrm{CK}$ treatment was the lowest, which indicates that certain fertilizers can be used to improve the soil nitrate content. The soil nitrogen was mainly concentrated in the $0-40 \mathrm{~cm}$ soil layer for accumulation, which is conducive to the absorption of nutrients by wheat in the regreening period. 


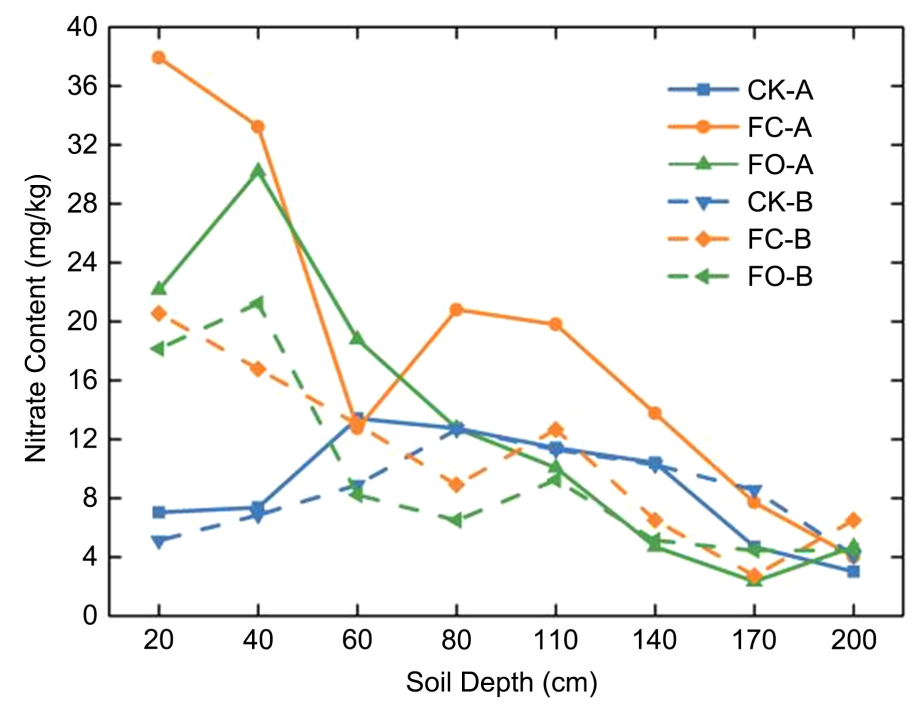

Figure 1. The soil nitrate content in the regreening stage.

Under the different fertilization levels, regardless of whether traditional irrigation (A) or water-saving irrigation (B) was used, the soil nitrate content in the 0 $-140 \mathrm{~cm}$ soil layer was higher than that in the $140-170 \mathrm{~cm}$ soil layer. However, in the traditional irrigation treatment (A), the nitrate content in the $80-110 \mathrm{~cm}$ soil layer was higher than that in the water-saving irrigation treatment (B) by the different treatments. Therefore, the topdressing and irrigation of winter wheat should be appropriate. Otherwise, it is easy to cause leaching, and long-term accumulation will threaten the nitrate content of groundwater.

After the winter wheat entered the jointing stage (Figure 2), the growth rate accelerated and the plants entered the vigorous growth period, and the absorption intensity of nutrients increased. The top dressing and irrigation in the jointing stage increased the soil nitrate content to a certain extent. The change in the $40 \mathrm{~cm}$ soil layer under the different treatments was the most dramatic. The soil nitrate content in the $0-80 \mathrm{~cm}$ soil layer under the different treatments decreases gradually with increasing soil depth. The nitrate content in the $80-200$ $\mathrm{cm}$ soil layer was significantly lower than that in the $0-60 \mathrm{~cm}$ soil layer. In the jointing stage of winter wheat, the nitrate content in the $0-110 \mathrm{~cm}$ soil layer under the FO treatment decreased to different degrees compared with the $\mathrm{CK}$ treatment. The reduction ranges of the traditional irrigation (A) and water-saving irrigation (B) treatments were $2.24 \%-23.00 \%$ and $4.61 \%-32.97 \%$, respectively. The reason is that the optimized fertilization treatment can meet the nutrient requirement of wheat in the jointing stage, and excessive fertilization will cause nitrogen fertilizer waster.

In the wheat flowering stage, the change trend of the soil nitrate content was roughly the same (Figure 3), and the nitrate content and cumulated amount in the $0-40 \mathrm{~cm}$ soil layer was higher. Under the different fertilization conditions, regardless of whether traditional irrigation (A) or water-saving irrigation (B) was used, the soil in the $0-60 \mathrm{~cm}$ soil layer shows that the trend in the nitrate 


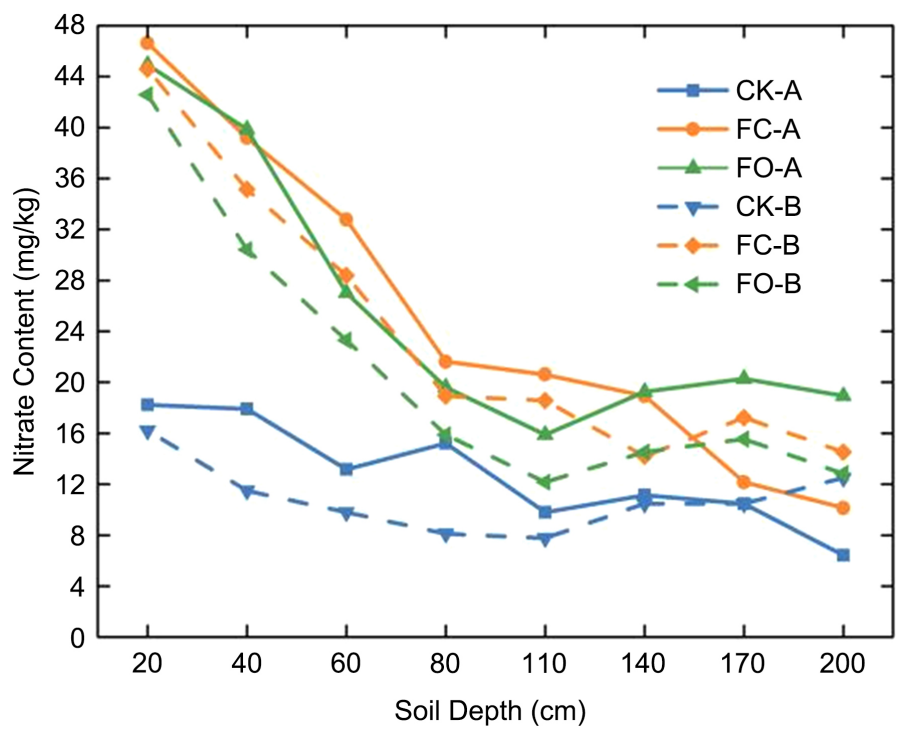

Figure 2. The soil nitrate content in the jointing stage.

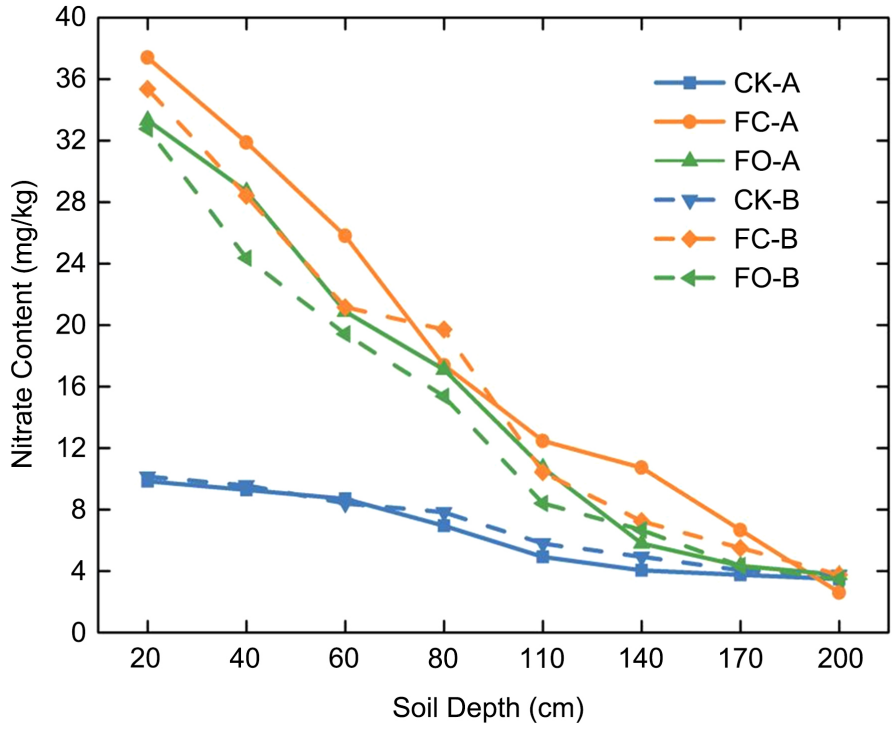

Figure 3. The soil nitrate content in the flowering stage.

concentration increased gradually with increasing nitrogen application rate, and the amount of migration to the soil layer below $60 \mathrm{~cm}$ was lower. The pattern presented by the different treatments was $\mathrm{FC}>\mathrm{FO}$, indicating that the nitrate content and the cumulated amount of increasing nitrogen fertilizer increased and increased with the increase in the nitrogen application rate. Under the two irrigation methods, the nitrate content between the $140-200 \mathrm{~cm}$ soil layer under the different treatments followed the pattern of FC $>$ FO.

From the flowering stage to the grain filling stage (Figure 4), the absorption intensity of nitrogen in the winter wheat decreased gradually, resulting in the accumulation of nitrate in the soil surface with a higher content. Compared with the flowering stage, under the two irrigation methods, the soil layer with a high 


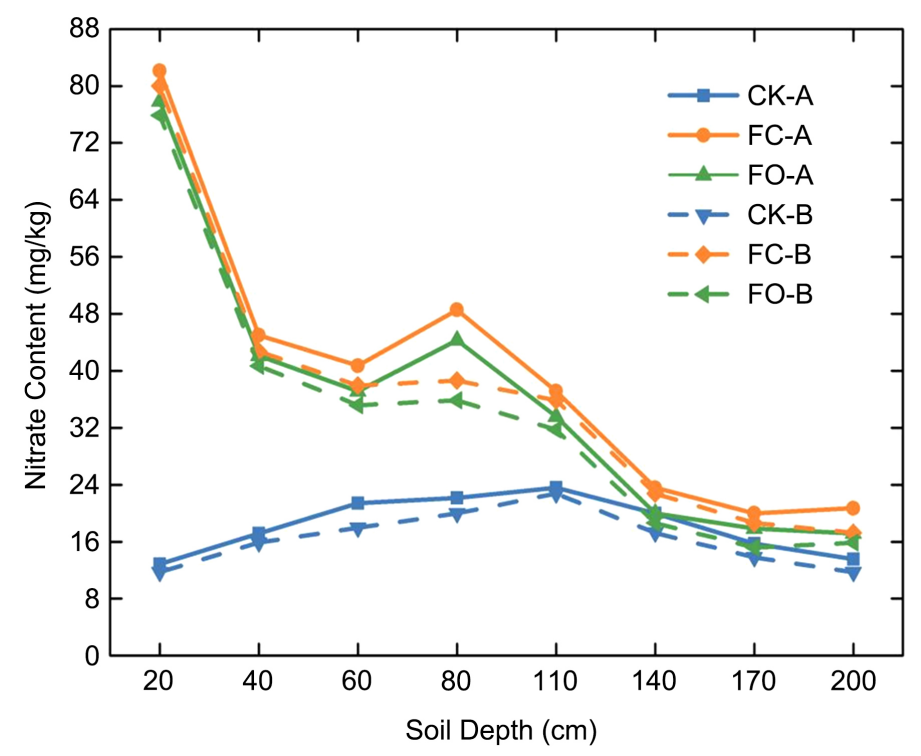

Figure 4. The soil nitrate content in the grain filling stage.

soil nitrate content in the grain filling stage moved down to the $80-110 \mathrm{~cm}$ soil layer, indicating that with the advancement of the growth period, soil nitrate has a tendency to move down, but the decrease range of the water-saving irrigation treatment was less than that of the traditional irrigation treatment. Regardless of whether traditional irrigation or water-saving irrigation was used, the nitrate content in soil layers in the different treatments followed the pattern of FC > FO, indicating that fertilization aggravates the downward leaching of nitrate in soil.

From the grain filling stage to the mature stage (Figure 5), under the two irrigation methods, the nitrate in the $0-200 \mathrm{~cm}$ soil layer increased with different degrees compared with the grain filling stage under both irrigation methods, but there was little difference in the nitrate during the two stages. However, there was a trend "from low to high, then from high to low" in the individual soil layers. In the control treatment, fertilizer deficiency hindered the growth and development of the wheat, resulting in the poor growth of the wheat roots, and therefore, the nitrate in the deep soil could not be absorbed by the crops. Under the different levels of nitrogen application, regardless of whether water-saving irrigation (B) or traditional irrigation (A) was used, in the wheat in the mature stage by the FC treatment, nitrate leached into the $20-200 \mathrm{~cm}$ deep soil layer, and in the wheat in the other treatments, nitrate leached into the $20-110 \mathrm{~cm}$ soil layer. In addition to the $\mathrm{CK}$ treatment, the leaching amount of nitrate in the 20 $110 \mathrm{~cm}$ soil layer followed the pattern of FC > FO, which may be due to the lower requirement for nitrogen fertilizer and moisture in the mature stage compared with the different treatments. The wheat in the mature stage coincides with the rainy season, and the nitrate in the soil will leach downward with the soil water. The FC treatment results in the large leaching amount of nitrate in the deep soils. Application of optimized fertilization can reduce the leaching amount of nitrate in deep soils. 


\subsection{Nitrogen Absorption and Utilizationby Plants}

The nitrogen accumulation of winter wheat in the different growth stages is shown in Table 2. The nitrogen content of winter wheat in the earlier growing stage gradually increased and then increased rapidly after entering the regreening stage, reaching the maximum value at the grain filling stage. It decreased significantly soon afterwards, and the accumulated nitrogen amount was $74.07 \%$ to $87.43 \%$ of the maximum accumulated amount in the mature stage. Regardless of whether traditional irrigation (B) or water-saving irrigation (A) was used, under the different nitrogen application levels, the nitrogen content in the different treatments followed the pattern of FO $>$ FC $>$ CK. In the wheat seedling stage, the nitrogen uptake is lower, which increases significantly in the organ formation stage. There are nitrogen losses in the grain formation stage. On the one hand, regarding nitrogen losses in crops, guttation, secretion of the roots and the natural shedding of senescent organs have emerged as causes. On the other hand, in the later stages of growth, the crops also release nitrogen into the air in the form of gaseous nitrogen, which may be due to the crop's redundant autogenous regulation of nitrogen. This aspect is not yet clear and needs to be further studied.

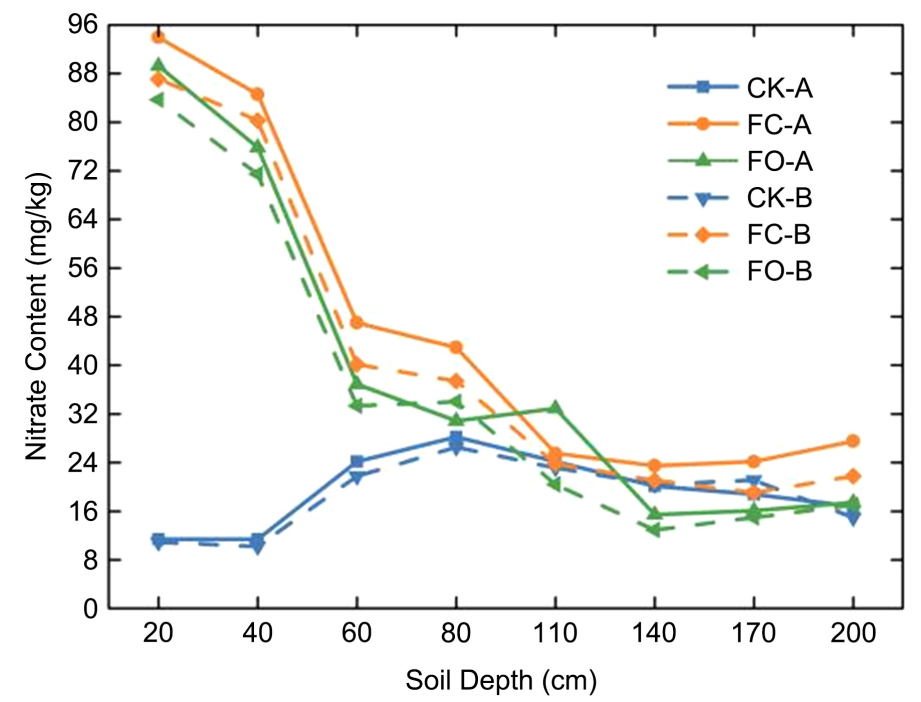

Figure 5. The soil nitrate content in the maturation stage.

Table 2. Uptake of nitrogen in wheat in the above-ground part.

\begin{tabular}{|c|c|c|c|c|c|c|}
\hline \multirow{2}{*}{ Nutrient } & \multirow{2}{*}{ Treatment } & \multicolumn{5}{|c|}{ Uptake of nitrogen in winter wheat $\left(\mathrm{kg} / \mathrm{hm}^{2}\right)$} \\
\hline & & Regreening stage & Jointing stage & Flowering stage & Grain filling stage & Maturation stage \\
\hline \multirow{6}{*}{$\mathrm{N}$} & CK-A & 45.32 & 66.50 & 110.14 & 125.11 & 95.42 \\
\hline & FC-A & 85.90 & 117.74 & 176.23 & 218.32 & 164.20 \\
\hline & FO-A & 90.31 & 115.64 & 190.28 & 237.20 & 185.69 \\
\hline & CK-B & 64.28 & 83.16 & 124.50 & 151.46 & 115.94 \\
\hline & FC-B & 102.13 & 137.20 & 189.45 & 235.38 & 174.35 \\
\hline & FO-B & 117.31 & 146.54 & 218.70 & 306.57 & 238.60 \\
\hline
\end{tabular}




\section{Conclusion}

In view of the short-term population growth in China, adding nitrogen fertilizer is still the guarantee of increasing grain yield in China. The water-saving irrigation mode had significantly better nitrate absorption efficiency of soil. The water-saving model is more conducive to improving the nitrogen absorption efficiency by the soil. This also confirms that excessive water use under traditional irrigation mode does not help improve nitrogen efficiency. For crops, the nitrate accumulation in the $0-90 \mathrm{~cm}$ soil layer can reach a minimum of $200 \mathrm{~kg} / \mathrm{hm}^{2}$ by using water-saving optimization of fertilization models, which reduces the possibility of large amounts of nitrate leaching in the crop growth stage. We also found that in the wheat harvest stage, the accumulated amount of nitrate in the $120-200 \mathrm{~cm}$ soil layer can reach $137-200 \mathrm{~kg} / \mathrm{hm}^{2}$. The amount of nitrate can not be utilized for the next year as the winter wheat rhizome only 60 to $80 \mathrm{~cm}$. Perhaps maize rotation could reuse leached nitrogen. Further study on the utilization of nitrate under $120 \mathrm{~cm}$ soil layer is required in the next stage.

\section{Acknowledgements}

The author would like to thank the help from Prof. Hongda Wen of Hebei Agricultural University and his research team.

\section{Conflicts of Interest}

The authors declare no conflicts of interest.

\section{References}

[1] Wu, P.T. and Feng, H. (2005) A Preliminary Study on the Development Strategy of Water-Saving Agriculture in China. Transactions of the Chinese Society of Agricultural Engineering, 6, 152-157.

[2] Wang, J.S., Jiao, X.Y., et al. (2016) Effects of Different Irrigation Periods and Nitrogen Application Rates on Water Use and Yield of Sorghum. Journal of Shanxi Agricultural Sciences, 6, 777-783

[3] Arheimer, B. and Lidén, R. (2000) Nitrogen and Phosphorus Concentrations from Agricultural Catchments Influence of Spatial and Temporal Variables. Journal of Hydrology, 227, 140-159. https://doi.org/10.1016/S0022-1694(99)00177-8

[4] Li, J.R., Chen, L.D., Fu, B.J., et al. (2002) Temporal and spatial variation characteristics of non-point source nitrogen in surface water of Yuqiao Reservoir. Scientia Geographica Sinica, 2, 238-242.

[5] Tapiavargas, M., Tiscarenolopez, M., Stone, J.J., et al. (2001) Tillage System Effects on Runoff and Sediment Yield in Hill Slope Agriculture. Field Crops Research, 69, 173-182. https://doi.org/10.1016/S0378-4290(00)00139-8

[6] Wang, X., Li, X.L., Zhang, M., et al. (2008) Reasons for Agricultural Non-Point Source Pollution and Strategies for Developing Sustainable Ecological Agriculture in Zigui County, the Three Gorges Reservoir Area. Bulletin of Agricultural Science and Technology, 12, 98-100.

[7] Matson, A.A., Naylor, R. and Ortiz-Monasterio, I. (1998) Integration of Environmental, Agronomic, and Economic Aspects of Fertilizer Management. Science, 280, 
112-115. https://doi.org/10.1126/science.280.5360.112

[8] Wolfe, D.W., Henderson, D.W., Hsiao, T.C., et al. (1988) Interactive Water and Nitrogen Effects on Senescence of Maize. I. Leaf Area Duration, Nitrogen Distribution, and Yield. Agronomy Journal, 80, 859-864.

https://doi.org/10.2134/agronj1988.00021962008000060004x

[9] Howell, T.A. (2001) Enhancing Water Use Efficiency in Irrigated Agriculture. Agronomy Journal, 93, 281-289. https://doi.org/10.2134/agronj2001.932281x

[10] Zhao, J.B., Chen, M., Li, J.W. and Zhou, J.H. (2020) Effect of Water and Fertilizer Regulation on the Soil Available P Content in Winter Wheat at West Lake Plain and Baiyang Lake in China. Open Access Library Journal, 7, 1-10.

https://doi.org/10.4236/oalib.1106774 